\title{
THE EFFECT OF THERMAL TREATMENT ON SCC OF ALLOY 718:
}

\section{A STRUCTURE - PROPERTIES STUDY}

\author{
M.G. Burke, T.R. Mager, M.T. Miglin ${ }^{+}$and J.L. Nelson ${ }^{*}$ \\ Westinghouse Electric Corp. \\ Pittsburgh, PA 15235 \\ ${ }^{+}$Babcock \& Wilcox Research \& Development Division \\ Alliance, $\mathrm{OH} 44601$ \\ * Electric Power Research Institute \\ Palo Alto, CA 94304
}

\begin{abstract}
The stress corrosion cracking (SCC) behavior of alloy 718 is known to be controlled by the microstructure of the material. By evaluating the SCC susceptibility of alloy 718 as a function of thermal treatment and by characterizing the microstructure produced during various thermal treatments, it has been possible to identify those particular phases which are deleterious to SCC performance. The SCC response of two materials, conventional alloy 718 and "Ticolloy" has been evaluated using $\mathrm{K}_{1 \mathrm{SCC}}$ tests conducted in PWR water at $360^{\circ} \mathrm{C}$. Complimentary microstructural analysis of the various materials has been conducted using analytical electron microscopy techniques. The results show that the optimum SCC performance is related to a "clean" microstructure containing only fine $\gamma^{\prime \prime}$ and $\gamma$ ' precipitates.
\end{abstract}

\footnotetext{
Superalloys 718, 625,706 and Various Derivatives Edited by E.A. Loria

The Minerals, Metals \& Materials Society, 1994
} 


\section{INTRODUCTION}

Alloy 718, a Nb-modified Ni-Cr-Fe superalloy, is used in various light water reactor and gas turbine components that require high strength and good corrosion resistance. Of particular importance in nuclear and gas turbine applications is the stress corrosion behavior of alloy 718. The stress corrosion behavior of alloy 718 is strongly affected by the microstructure of the material. It is. therefore, important to identify those specific microstructural features that are associated with good performance and with poor performance, and to then design an appropriate thermal treatment to produce the optimum microstructure to resist stress corrosion.

Several contradictory time-temperature-transformation (TTT) diagrams exist in the literature for alloy 718; however, the TTT diagram presented in Figure 1 [1] is in closest agreement with previous analytical electron microscopy (AEM)/atom probe field-ion microscopy (APFIM) investigations of alloy 718. [2] The primary strengthening phases in alloy 718 are the $\mathrm{DO}_{22}$-ordered $\gamma^{\prime \prime}\left(\mathrm{Ni}_{3} \mathrm{Nb}\right.$-type) and the $\mathrm{L}_{2}$-ordered $\gamma^{\prime}\left(\mathrm{Ni}_{3} \mathrm{Al}\right.$-type $)$. These precipitates are coherent with the $\gamma$ matrix. Atom probe microanalysis has shown that the compositions of these precipitates are more correctly specified as $\mathrm{Ni}_{3}(\mathrm{Nb}, \mathrm{Ti}, \mathrm{Al})$ and $\mathrm{Ni}_{3}(\mathrm{Ti}, \mathrm{Al}, \mathrm{Nb})$ for the $\gamma^{\prime \prime}$ and $\gamma^{\prime}$, respectively, with the $\gamma^{\prime \prime}$ containing more $\mathrm{Nb}$ and Ti than the $\gamma^{\prime}$. [2] Other phases which form in alloy 718 include the $\mathrm{DO}_{\mathrm{a}}$-ordered $\delta\left(\mathrm{Ni}_{3} \mathrm{Nb}\right.$-type $), \mathrm{C} 14$-ordered Laves phase, and MC-type carbides. Importantly, certain phases such as Laves have been reported to deleteriously affect the SCC behavior of alloy 718.[3] Similar observations have been made concerning the role of $\delta$.

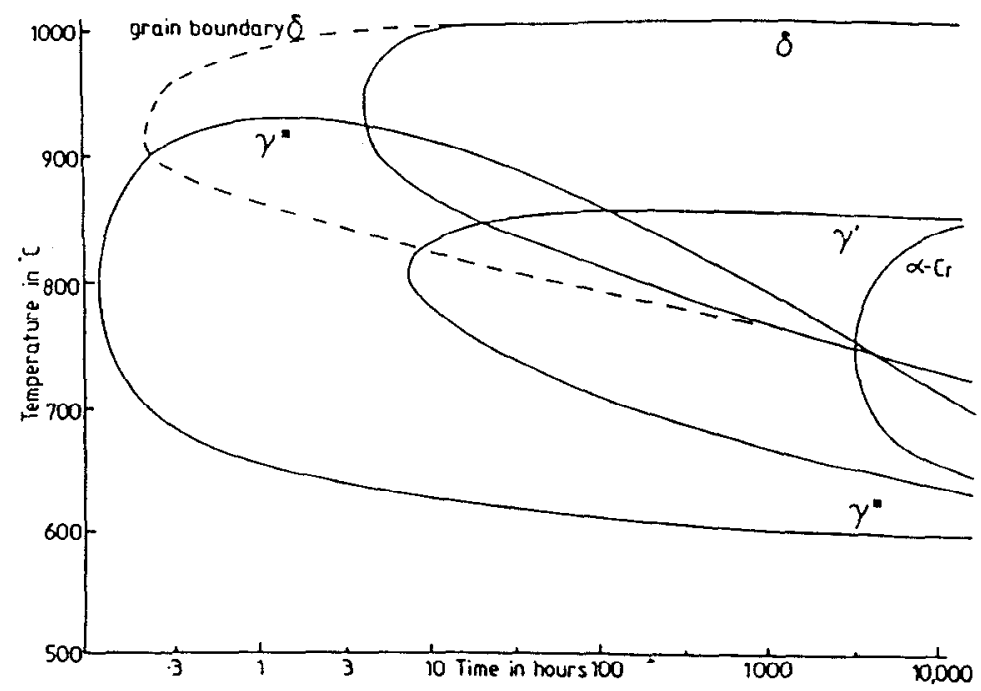

Figure 1. TTT Diagram for alloy 718 from Ref. 1. 
The failure of in-core components fabricated from alloy 718 has been attributed to intergranular stress corrosion cracking (IGSCC). In general, in-core components are given a thermal treatment that is based upon the typical treatments which had been previously developed for aerospace applications. In order to optimize the performance of alloy 718 for nuclear applications, the Electric Power Research Institute has sponsored a structureproperties program which has examined the effect of melt practice, heat treatment, and alloy chemistry on the SCC behavior of "alloy 718" materials. [4-6]

The stress corrosion performance of the materials examined in this study was determined by

the constant displacement rate $\mathrm{K}_{1 \mathrm{SCC}}$ test, also termed the "rising load test". Standard fracture toughness specimen geometries are used for this test. The benefit of this test is that SCC growth rate versus applied stress intensity data are available from a single specimen in approximately three weeks as opposed to more lengthy multi-specimen test methods.

In parallel with the $\mathrm{K}_{1 \mathrm{SCC}}$ tests, an analytical electron microscopy investigation was conducted to thoroughly characterize the microstructures of the alloy 718 materials. The purpose of this investigation was to identify the specific features present in the materials as a function of heat treatment and alloy chemistry, and to compare these microstructural features to the observed IGSCC behavior. The objective of this program was to obtain a correlation between specific microstructural features and IGSCC behavior.

\section{EXPERIMENTAL}

Two alloy 718 variants were studied in this investigation. Their compositions are listed in Table I. The "commercial heat" of alloy 718 (718-DA) was vacuum-induction melted (VIM), electroslag-remelted (ESR), and direct-age (DA) processed. Although the DA forge practice produced a fine-grained microstructure, the elevated temperatures required to dissolve the existing $\delta$ precipitates promoted significant grain growth. Thus, the SCC data reported for the DA processed material should be applicable to conventionally processed alloy 718 . In addition to the "commercial heat", an experimental alloy developed at the University of Texas, Ticolloy, was evaluated. "Ticolloy" has an increased $\mathrm{Al} / \mathrm{Ti}$ and $(\mathrm{Al}+\mathrm{Ti}) / \mathrm{Nb}$ ratios over conventional alloy 718.[7] Alloy 718-DA Forge material was examined in three thermally treated conditions, listed in Table II. For comparison, specimens of "Ticolloy" were evaluated in the AERO condition $\left(1093^{\circ} \mathrm{C} / 1 \mathrm{~h} / \mathrm{WQ}+718^{\circ} \mathrm{C} / 8 \mathrm{~h}+621^{\circ} \mathrm{C} / 6 \mathrm{~h} / \mathrm{AC}\right)$. Table II also lists the hardness measured for each condition.

\section{Stress Corrosion Cracking}

The specimens used for the SCC tests were $12.5 \mathrm{~mm}$ thick compact fracture specimens fabricated in the L-C orientation as described in ASTM Test for Plane-Strain Fracture 
TABLE I. ALLOY COMPOSITION (wt.\%)

$\begin{array}{lcc} & \text { Alloy 718-DA Forgc } & \text { Ticolloy } \\ & 51.5 & 53.93 \\ \mathrm{Cr} & 17.6 & 17.5 \\ \mathrm{Fe} & 20.9 & 17.8 \\ \mathrm{Ti} & 1.05 & 0.96 \\ \mathrm{Al} & 0.55 & 0.94 \\ \mathrm{Nb}+\mathrm{Ta} & 5.21 & 5.74 \\ \mathrm{Mo} & 2.92 & 3.05 \\ \mathrm{Mn} & 0.08 & 0.02 \\ \mathrm{Si} & 0.09 & 0.11 \\ \mathrm{C} & 0.04 & 0.03 \\ \mathrm{~S} & 0.0004 & 0.002 \\ \mathrm{Co} & 0.32 & --- \\ \mathrm{B} & 0.004 & 0.003 \\ \mathrm{Cu} & 0.05 & 0.01 \\ \mathrm{P} & 0.005 & 0.006\end{array}$

TABLE II. HEAT TREATMENTS

\begin{tabular}{|c|c|c|c|}
\hline Heat & Specimen ID & Hardness, $R_{c}$ & $\underline{\text { Heat Treatment }}$ \\
\hline \multirow[t]{3}{*}{ DA-718 } & DA-CONV & 44 & $982^{\circ} \mathrm{C} / 1 \mathrm{~h} / \mathrm{AC}+718^{\circ} \mathrm{C} / 8 \mathrm{~h}+621^{\circ} \mathrm{C} / 8 \mathrm{~h} / \mathrm{AC}$ \\
\hline & DA-AERO & 41 & $1093^{\circ} \mathrm{C} / 2 \mathrm{~h} / \mathrm{WQ}+718^{\circ} \mathrm{C} / 8 \mathrm{~h}+621^{\circ} \mathrm{C} / 8 \mathrm{~h} / \mathrm{AC}$ \\
\hline & DA-2Age & 37 & $1093^{\circ} \mathrm{C} / 2 \mathrm{~h} / \mathrm{WA}+663^{\circ} \mathrm{C} / 100 \mathrm{~h} / \mathrm{AC}$ \\
\hline colloy & TY-AERO & 34 & Same as DA-AERO \\
\hline
\end{tabular}

TABLE III. PRIMARY WATER SPECIFICATIONS

$\begin{array}{ll}\text { Dissolved Oxygen } & \leq 0.01 \mathrm{ppm} \\ \text { Boric Acid } & 5700 \mathrm{ppm}( \pm 500 \mathrm{ppm}) \\ \text { Lithium } & 2 \mathrm{ppm} \\ \mathrm{pH} & 6.5( \pm 0.5) \\ \text { Conductivity } & <20 \mu \mathrm{mhos} / \mathrm{cm} \\ \text { Dissoslved Hydrogen } & 15-50 \mathrm{Std} \mathrm{cc} / \mathrm{kg} \mathrm{H}_{2} \mathrm{O} \\ \text { Chloride } & <0.1 \mathrm{ppm} \\ \text { Fluoride } & <0.1 \mathrm{ppm}\end{array}$


Toughness of Metallic Materials (E399-83). The specimens were fatigue pre-cracked in air, with a final stress intensity range below $20 \mathrm{MPa} \sqrt{\mathrm{m}}$ for each specimen. The specimen loading fixture, described elsewhere [8], was affixed to an autoclave mountcd in a load frame with a screw-driven actuator. The test environment was $360^{\circ} \mathrm{C}$ PWR primary side water, Table III. A constant displacement rate of $1.3 \times 10^{-9} \mathrm{~m} / \mathrm{s}$ was selected for the SCC tests based upon a displacement rate matrix conducted for alloy 718 in PWR water by Miglin and Nelson. [9] The SCC crack length was monitored during each test using the reversing DC potential drop technique and a current of 10A. [10] A continuous record of the load, crack length and displacement versus time was obtained for each specimen during the test. The data were subsequently converted to a graph of crack growth rate versus stress intensity, as described in reference 8. All cracked specimens were examined using scanning electron microscopy techniques to evaluate the fracture morphology.

\section{Analytical Electron Microscopy}

Thin-foil specimens were prepared by conventional electropolishing techniques in an electrolyte of $10 \%$ perchloric acid-90\% methanol. Electron-transparent samples were subsequently examined in a Philips EM400T or a CM12 analytical electron microscope equipped with a Link Analytical LZ5 windowless energy dispersive x-ray spectrometer and an AN10/85S analyzer. Both energy dispersive $\mathrm{x}$-ray microanalysis and electron diffraction techniques were employed for phase identification.

\section{RESULTS AND DISCUSSION}

\section{Stress Corrosion Cracking}

The results of the SCC tests are shown in Figure 2. All specimens with the exception of DA2Age, failed as a result of IGSCC. A comparison of the SCC results for the DA-CONV and DA-AERO specimens demonstrates the bencficial effect of the higher solution annealing temperature. The "Ticolloy" AERO material showed an improvement in SCC behavior over the conventional alloy 718 specimens for both the standard and Aero thermal treatments.

\section{Analytical Electron Microscopy}

The conventional thermal treatment with a $982^{\circ} \mathrm{C}$ anneal results in the precipitation of intergranular $\delta$. Pre-existing $\delta$ which had formed during prior thermomechanical processing of the material is not dissolved by this low temperature anneal. Figure 3 shows a typical $\delta$ morphology observed in alloy 718 which had been given the conventional heat treatment. 


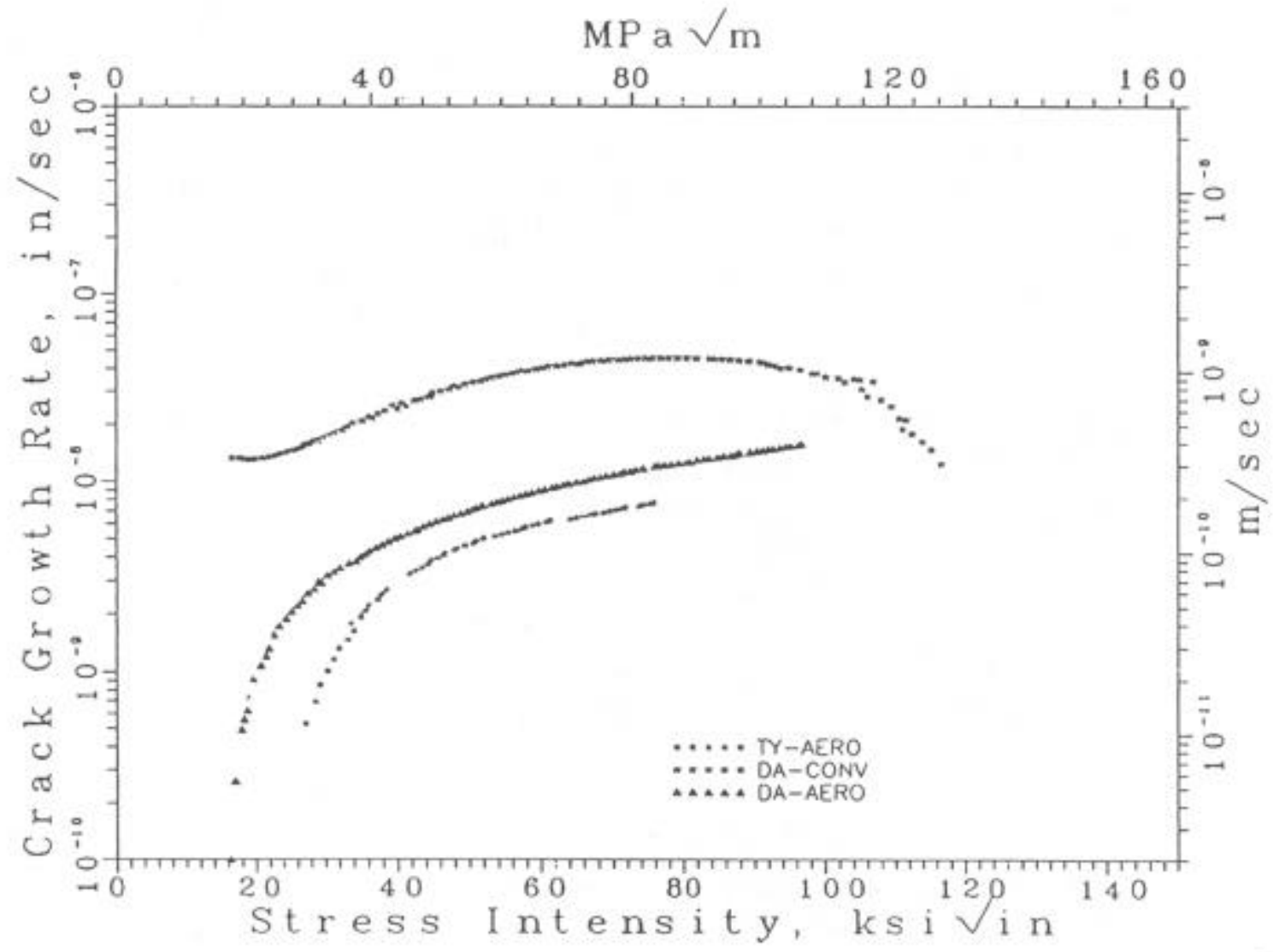

Figure 2. Crack growth rate versus applied stress intensity for the alloy 718 and "Ticolloy" specimens tested in the $360^{\circ} \mathrm{C}$ PWR environment.

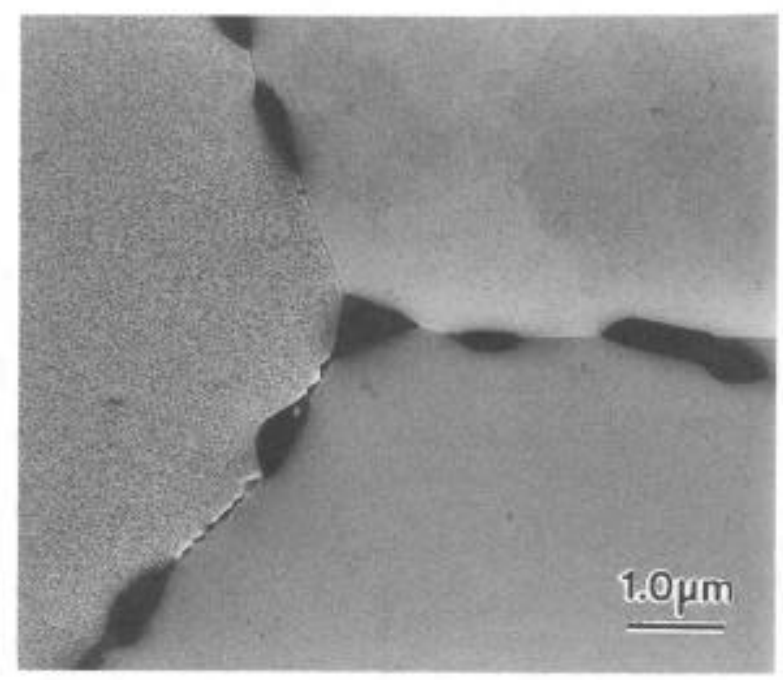

Figure 3. Transmission electron micrograph of alloy 718 aged at $982^{\circ} \mathrm{C}$ for 1 hour prior to the conventional two-stage $718^{\circ} \mathrm{C} / 621^{\circ} \mathrm{C}$ ageing treatment. Note the presence of fine intergranular and coarse globular $\delta$. 


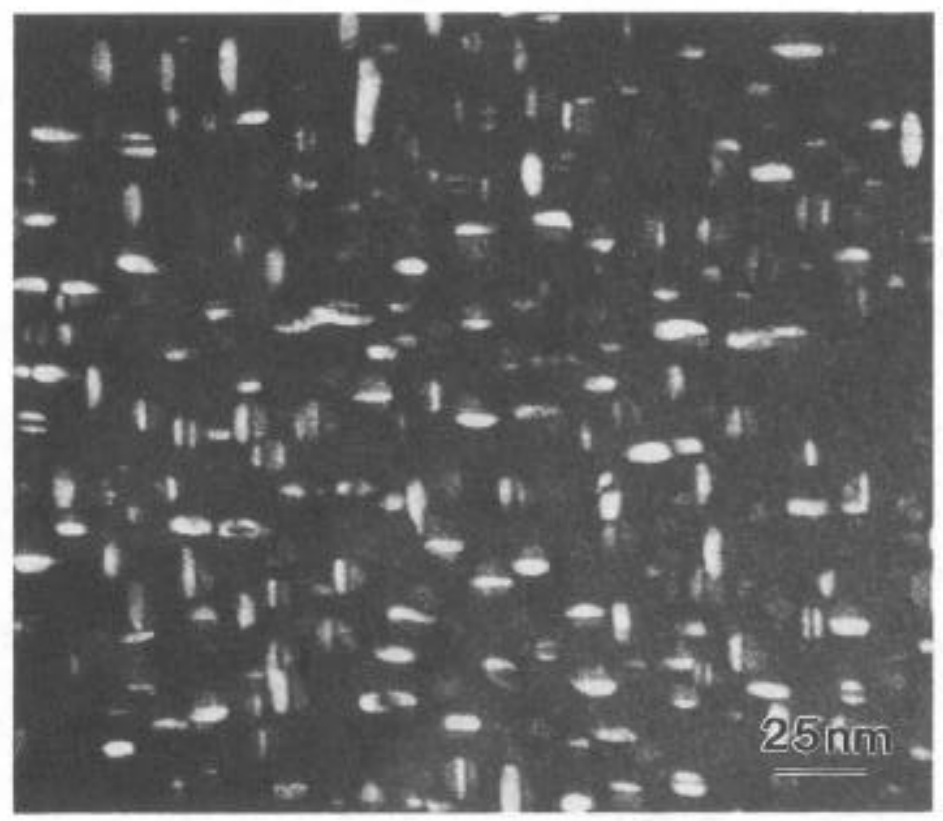

Figure 4. Dark-field transmission electron micrograph of the fine $\gamma^{\prime \prime}$ and $\gamma^{*}$ precipitates formed in the DA-2Age material. Two $<100>$ variants of the $\gamma^{\prime \prime}$ precipitates are visible in this [001]-oriented specimen.
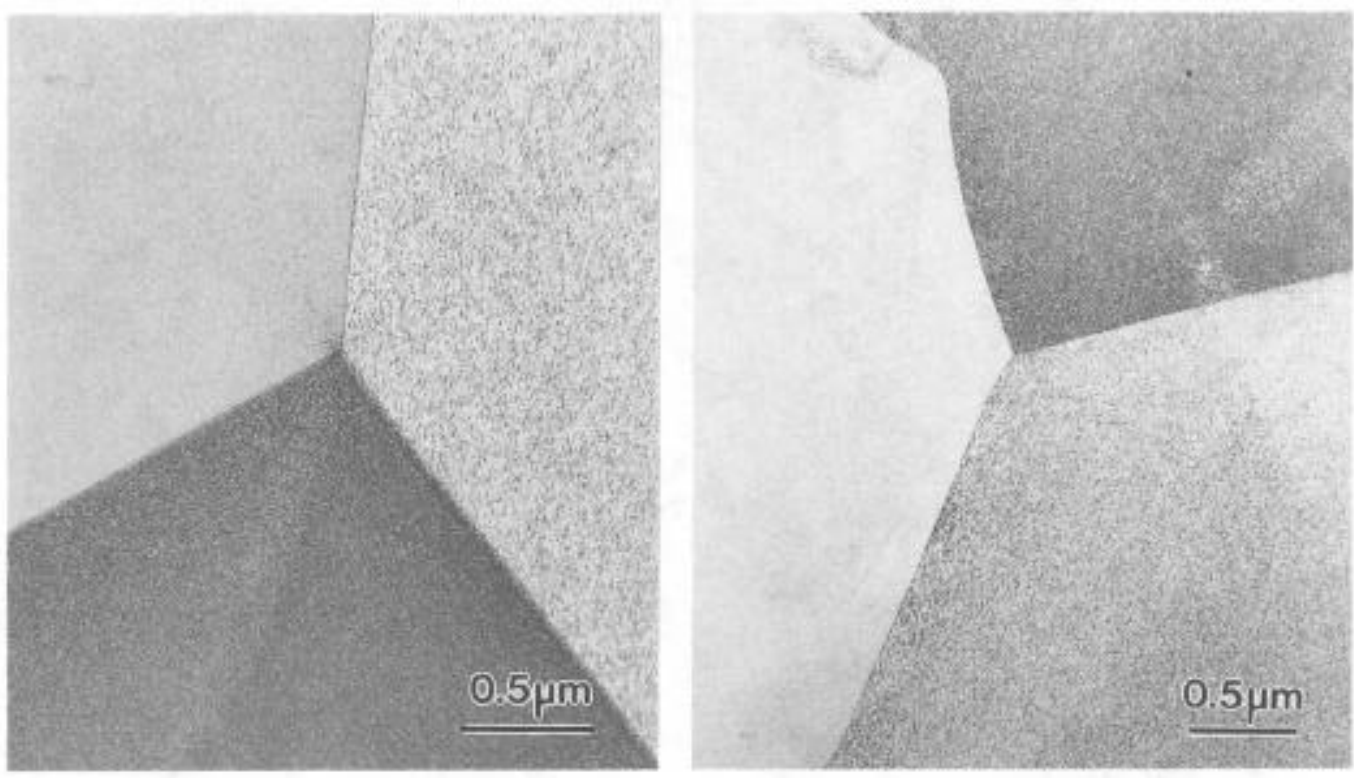

Figure 5. Transmission electron micrographs showing the $\delta$-free grain boundaries observed in the DA-Aero specimens. 


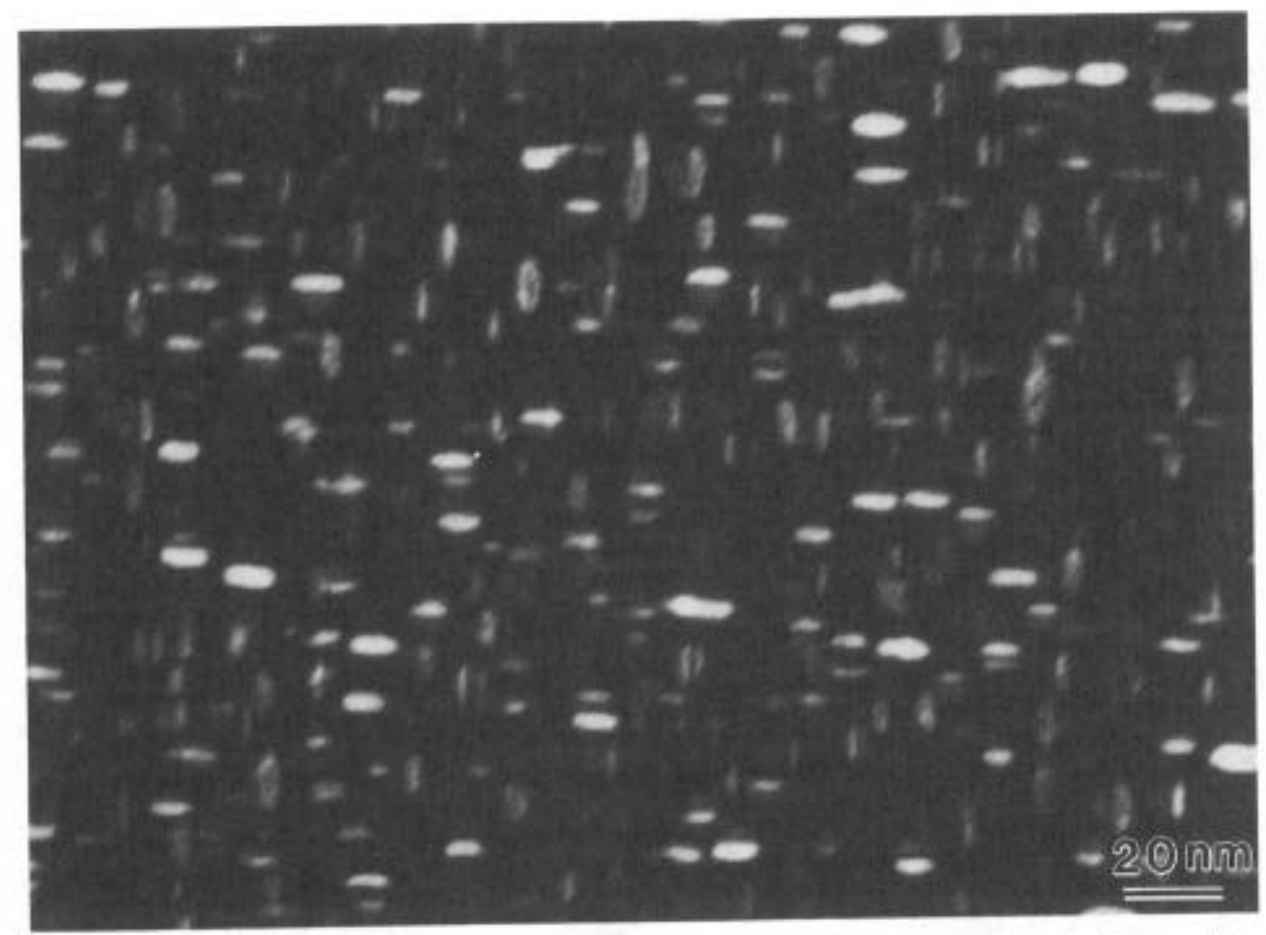

Figure 6. Dark-field transmission electron micrograph of the fine $\gamma^{\prime \prime}$ and $\gamma$ ' precipitates formed in the DA-Aero material. Two $<100>$ variants of the $\gamma$ " precipitates are visible in this [001]-oriented specimen.

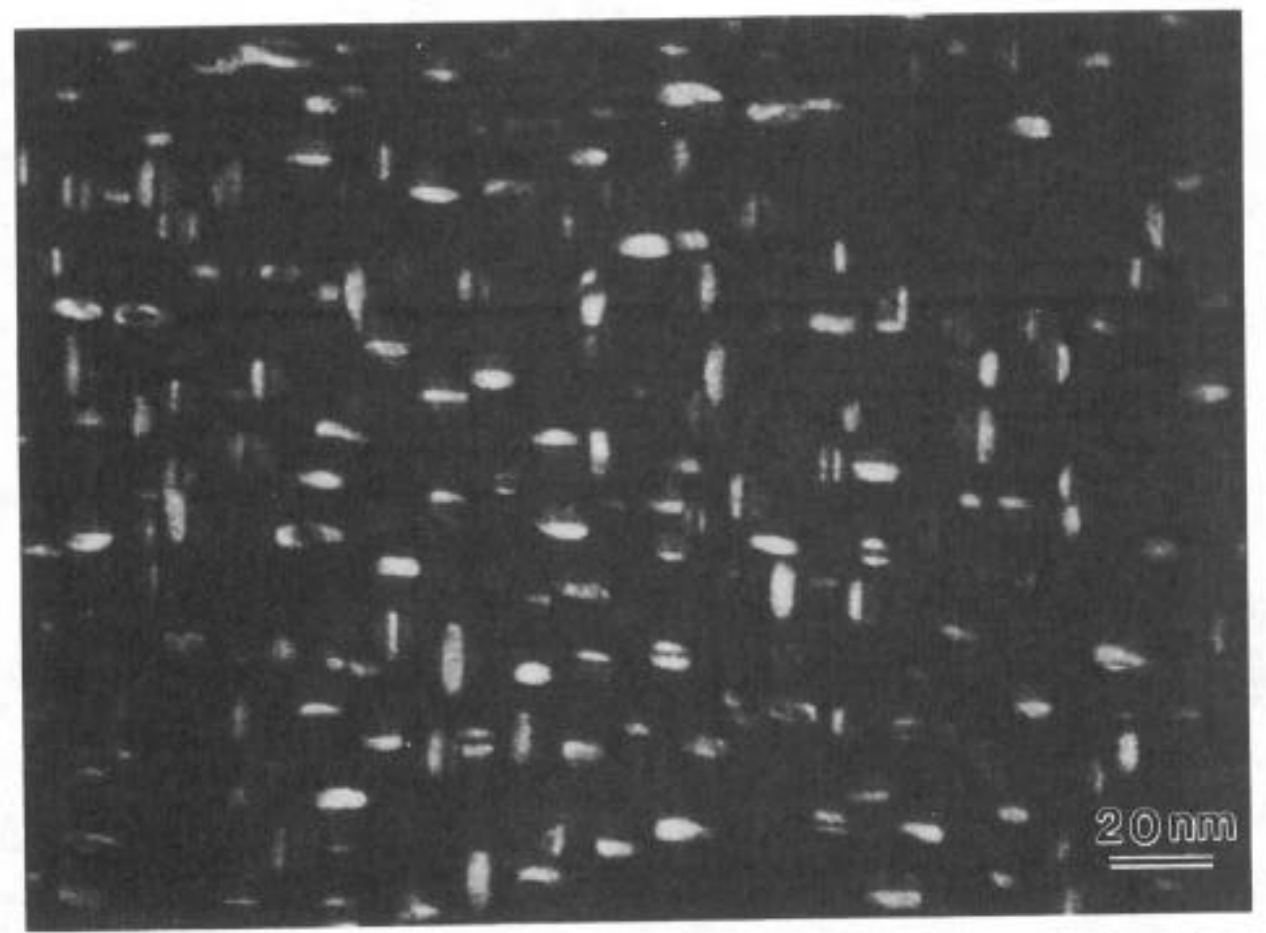

Figure 7. Dark-field transmission electron micrograph of the fine $\gamma^{\prime \prime}$ and $\gamma^{*}$ precipitates formed in the Ticolloy-Aero sample. Two $<100>$ variants of the $\gamma$ " precipitates are visible in this [001]-oriented specimen. 

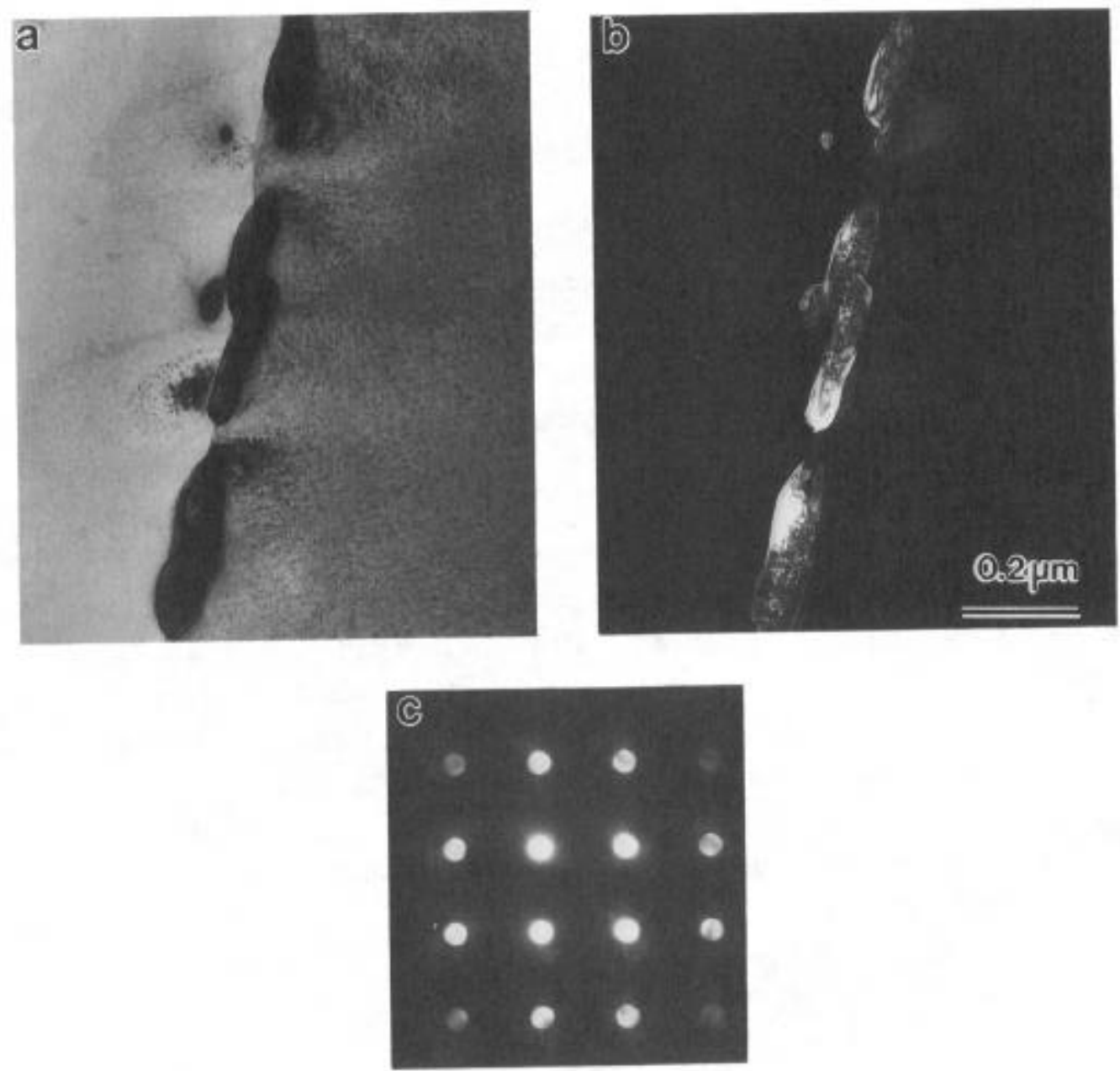

Figure 8. Complementary bright-field (a) and dark-field (b) transmission electron micrographs of the intergranular $\mathrm{NbC}$ precipitates observed in Ticolloy-Aero. (c) Corresponding convergent beam electron diffraction pattern. 
The subsequent heat treatment resulted in the precipitation of fine intra- and intergranular $\gamma^{\prime \prime}$ and intragranular $\gamma$ '.

The DA-2Age treatment with the prolonged $718^{\circ} \mathrm{C}$ age was also characterized by a uniform distribution of fine $\gamma^{\prime \prime}$ and $\gamma^{\prime}$ precipitates, as evidenced in the micrograph in Figure 4. These precipitates ranged from 5 to $12 \mathrm{~nm}$ in size. No other features were observed in this material.

The Aero heat treatment with its high temperature anneal $\left(1038^{\circ} \mathrm{C}\right)$ produccs a $\delta$-frec microstructure in the DA material, Figure 5. Other than the occasional MC carbide which had pinned grain boundaries, the only precipitates observed along grain boundaries were fine $\gamma$ ". The matrix of this material was characterized by a uniform distribution of both fine $(5-13 \mathrm{~nm})$ $\gamma^{\prime \prime}$ and $\gamma^{\prime}$ precipitates, Figure 6.

The microstructure of the Ticolloy Aero specimens was similar to that of the 718 Aero material in that a uniform distribution of fine $\gamma^{\prime \prime}$ and $\gamma^{\prime}$ were observed throughout the matrix. The size of these precipitates ranged from 5 to $10 \mathrm{~nm}$, as shown in Figure 7. Unlike the 718 Aero specimens, the Ticolloy Aero samples contained intergranular NbC precipitates along some high angle grain boundaries, Figure 8 . Based upon the modified chemistry of "Ticolloy", it is anticipated that there are subtle variations in the $\gamma^{\text {" and }} \gamma$ ' compositions. Further analysis using APFIM techniques are necessary in order to resolve this point. Similarly, the SCC resistant samples (DA-2 $\Lambda$ ge) which were free of all phases other than $\gamma$ " and $\gamma^{\prime}$ merit additional study so that the question of precipitate chemistry changes during the prolonged ageing treatment may be resolved.

\section{SUMMARY}

The results of this SCC/microstructure study indicate that the optimum SCC performance is obtained in alloy 718 which is free of $\delta$ precipitates, Laves phase, and coarse MC-type inclusions. The $\delta$-free microstructures observed in materials which had been annealed at $1093^{\circ} \mathrm{C}$ do not ensure resistance to IGSCC, but do significantly improve their SCC behavior. The subtle effects of prolonged ageing at $718^{\circ} \mathrm{C}$ and $663^{\circ} \mathrm{C}$ on the $\gamma^{\prime \prime}$ and $\gamma^{\prime}$ compositions merit further analysis in order to explain the SCC immunity observed in this investigation.

\section{ACKNOWLEDGMENTS}

The expert technical assistance of J.J. Haugh in the preparation of samples for AEM analysis, and E.A. DeStephen in conducting the SCC tests, is greatly appreciated. This work was funded by EPRI Project RP3154-3. 


\section{REFERENCES}

1. J.W. Brooks and P.J. Bridges, in High Temperature Alloys for Gas Turbines and Other Applications, Betz et al., Eds. (D. Reidel Publishing Co., 1987) 1131.

2. M.G. Burke and M.K. Miller, "Precipitation in Alloy 718: A Combined AEM and APFIM Investigation," in Superalloys 718, 625 and Various Derivatives, TMSAIME, E.A. Loria, Ed., (TMS, 1991) 337-350.

3. I.L.W. Wilson and M.G. Burke,"The Effect of Microstructure on the SCC Behavior of Alloy 718," in Superalloys 718, 625 and Various Derivatives, TMS-AIME, E.A. Loria, Ed., (TMS, 1991) 681-693.

4. EPRI Program on SCC of Alloy 718: RP3154; Program Mandager: J.L. Nelson.

5. M.T. Miglin, J.V. Monter, C.S. Wade, J.K. Tien, and J.L. Nelson, "Stress Corrosion Cracking of Chemistry and Heat Treat Variants of Alloy 718- Part 1: Stress Corrosion Test Results," in Environmental Degradation of Materials in Nuclear Power Systems-Water Reactors, R.E. Gold and E.P. Simonen, Eds. (TMS, 1993) 815-819.

6. M.G. Burke, T.R. Mager, and J.L. Nelson, "Stress Corrosion Cracking of Chemistry and Heat Treat Variants of Alloy 718- Part 2: Microstructural Characterization," in Environmental Degradation of Materials in Nuclear Power Systems-Water Reactors, R.E. Gold and E.P. Simonen, Eds. (TMS, 1993) 821-827.

7. J.P. Collier, S.H. Wong, J.C. Phillips, and J.K. Tien, "The Effect of Varying Al, Ti, and Nb Content on the Phase Stability of INCONEL 718," Met. Trans. A, 19A, 1988, 1657-1666.

8. M.T. Miglin, J.V. Monter, C.S. Wade, and J.L. Nelson, "Improved Stress Corrosion Performance for Alloy 718 via Melt Practice and Heat Treatment," in Proceedings of the 12th International Conference on Corrosion, Houston, Texas (NACE, 1993) in press.

9. M.T. Miglin and J.L. Nelson, in Superalloys 718, 625 and Various Derivatives, TMS-AIME, E.A. Loria, Ed., (TMS, 1991) 695-740.

10. K.-H. Schwalbe and D. Hellman, J. Testing and Evaluation, 9, 1981, 218-220. 